\title{
Integrating gamification into website design to facilitate users' experiences - A case study on three museum websites
}

\author{
Hsieh, Hsiu-Ching, Associate Professor, Department of Creative Design, \\ National Yunlin University of Science and Technology \\ Lin, Yi-Yu, Graduate School of Creative Design, \\ National Yunlin University of Science and Technology
}

\begin{abstract}
This study aims to construct the gamification website module, study the gamification of museum websites, and apply case analyses to preliminarily verify the constructed module. First, research on gamification, website design, and user experience is analyzed and integrated to construct the gamification website design module to enhance user experience. Second, currently developed gamification cases of museum websites are used for the case analysis to verify the module. Third, the above module is further verified through user test and interview.
\end{abstract}

Key words: gamification, users' experiences, website design

\section{Research background and objective}

\section{A. Introduction}

Gamification arouses people's nature of play through games. The activity in the game process becomes more interesting, and the users are enhanced the participation motivation to rapidly achieve the effective learning. With the rapid development of technology nowadays, the popularity of networks and digital products provides good development environment for gamification. In face of above phenomena, the "gamification" integration design presents the necessity. "Games" are everywhere in our life. In the actual applications, designers start to integrate game experience into the interface design for broader presentation of gamification. Gamification is regarded as an effective factor, in many fields, in enhancing users' participation motivation and rapid learning. However, Gartner indicated in 2012 that $80 \%$ of the application of gamification by 2014 would not implement the original intention. The problem lied in developers over emphasizing the design of decoration, but not creating meaningful motivation and goals. Apparently, the former would lose the meaning without the support of the latter. For this reason, it should clearly understand the meaning of gamification and the use of gamification concepts when applying gamification concepts to achieve the optimal communication efficiency.

\section{B. Research objective}

1. To apply gamification design to enhance website design communication and user experience.

2. To construct a "module with the application of gamification to website design to enhance effective communication" to enhance user experience.

\section{Literature review}

The literature review in this study cuts in from gamification, website design, and user experience.

\section{A. Gamification}

Regardless the actual application or academic research, modern people have increased the interests in gamification. Nevertheless, there has not been a definite definition of gamification. In current literatures or actual application, the more acceptable definition of "gamification" is "to use video game elements in non-game contexts to enhance user experience and user engagement" (Deterding et al, 2011) as well as 'to attract users' engagement and problem solving through game thinking processes and game mechanisms (Zichermann \& Cunningham, 2011). Barr (2008) pointed out the difference between "game" and "play" that the former showed definite rules and goals, while the latter was the opposite. Such a definition was used for understanding the better and worse performance.

In fact, gamification is a "design strategy" applying game elements and mechanisms (Deterding et al, 2011) as well as a method uses the fun of game for enhancing participation motivation. For game players, the better performance is pursued under preset rules, i.e. game elements and mechanisms of interests, challenges, and accomplishment acquired from games. The presentation of gamification is flexible; any game elements could be regarded as a single and a mechanism to make rich combinations and changes. Gamification arouses people's nature of play to make activities in the game process become more interesting and to enhance users' participation motivation to rapidly achieve effective learning. With digital game mechanisms and experience design, people are attracted and encouraged to implement the goals (Garner Group, 2014).

Werbach (2014) regarded the process making activities be more similar to games as "gamification". The game mechanisms included in the basic elements in a game process contains points, badges, leaderboards, or levels (Werbach \& Hunter, 2012). Moreover, it is also inevitable to introduce social mechanisms into games to facilitate users' engagement in various parts. Such mechanisms could enhance users' service use and behavior change with external rewards (Zichermann \& Cunningham, 2011). Because of the word "game", gamification is often misunderstood as playing; however, it applies merely the minimum elements of games, i.e. scoring system, and there are goals behind games (Nicholson, 2012).

Gamification, applied to museum websites, attempts to the ideal goal by allowing readers more pleasantly understand the contents and meanings conveyed by the museum through museum games. 
B. Application of gamification to website design communication to facilitate communication efficiency

"Freedom to fail" is an element of gamification. In traditional learning environments, attempting errors is not encouraged. Nevertheless, learning in errors is a shortcut to enhance learning speed. Failure is the learning process, not the learning result. An alternative experience in the simulation of reality in games enriches the learning opportunities (Kapp, 2012). Learners seldom realize the factors in wrong answers or incorrect results and the possible improvement, but are simply noticed the failure for not advancing. Failure should be allowed and accepted and be a part of gamification design (Kapp, 2012). Gamification aims to allow players engaging more in tasks and being encouraged desirable behaviors (Prince, 2013). Zichermann and Cunningham (2011) defined gamification as the game thinking process and the utilization of game mechanisms allowing users' engagement and problem solving. Based on above definitions, Nicholson (2012) proposed three applications to construct user-centered meaningful gamification, allowing users feeling the fun of tasks and really establishing internalization experience. These mainly explain the possible effects of reward mechanisms on external motivation.

\section{User experience}

McCarthy and Wringht (2003) regarded experience as the "perception", stressing on the uniqueness of experience and the situations and conditions at the generation of experience. Experimental psychology explained experience as a single element before and after the activity process, such as motivation, trust, loathing, and fun. The "process of experience" is the set of such elements, emphasizing temporal experience processes and dynamic psychological conditions. User experience stands for the effect of the mutual effect between users and products, including aesthetic experience, meaningful experience, and emotional experience. Good user experience should satisfy users, provide product meanings, and induce users' feeling and emotion (Desmet \& Hekke, 2007).

\section{Construction of gamification website design module to enhance user experience}

Above ideas of user experience could be applied to gamification design to discuss the quality of user experience before, during, and after the interaction between users and products or physical equipment. The discussion focuses on the shaping process of user experience and the factors in user experience in the process. The efficiency core to apply gamification to website design communication lies in the physical design, covering game design principles, game mechanisms, game modes, game patterns, and game interface design elements. "User experience" in human-computer interaction and literatures on experience design are used for constructing the interactive experience design and further practicing users' experience responses and evaluation, which are further divided into four dimensions. The experience contents are (1)practicability: usability, efficiency, learnability, comprehension, (2)entertainment: pleasure, interest, controllability, sociability, narrative, (3)satisfaction: competition, autonomy, correlation, and (4)motivation: accomplishment, sociability, engagement. Finally, user experience is responded to the business to adjust the future gamification interactive experience design. It is a cycled process. From above literature review, the contexts are organized and drawn Figure 1, as below.

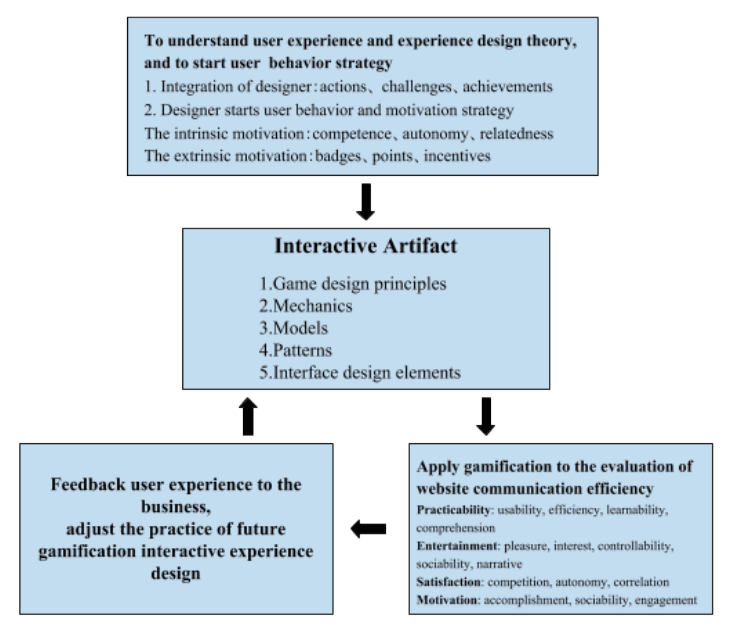

Fig. 1 The gamification website design module to enhance user experience

\section{Museum website and gamification}

People's nature of play is applied to education and learning, allowing people "learning from playing". A museum does not simply present the functions of exhibition and collection, but offers educational functions of information, education and learning, and academic research. Most people show the impression that the literature contents and the cultural meanings in a museum are dull and hard to understand. For this reason, some domestic museums apply gamification to museum websites and apply such gamification meanings to museum websites for users more pleasantly understand the contents and meanings conveyed by the museums to enhance user experience. Examples are shown as below.

Juming Museum, founded by Juming, a traditional craft master in Taiwan, is established a museum online guidance gamification website of "Mischievous Play Museum". In the homepage of the game, the situational animation with childlike illustration is applied to enhance players' interests (initiating users' behavior motivation). An "enter" button guides players entering the game mechanism, and the game is set 3 levels. The design elements contain mascots leading levels, illustrative maps, and sculpture works. The major idea is a puzzle game, in which mascots lead the players of game directions. Filling-in space is used as the game mechanism for stimulating audience to find out each sculpture so as to appreciate the beauty of Juming' works (Refer to Table 1). The players are given definite completion goals and time limit in the process and countdown sound stimulates players' nervousness to enhance the excitement and entertainment of the game. After the end of each level, the content meaning and explanatory feedback of each sculpture work are displayed to achieve the function of 


\section{Recent Developments on Information and Communication Technology (ICT) Engineering- Meen, Yang \& Zhao ISBN: 978-981-14-2136-5}

information provision. After beating a level, the reward mechanism encourages the players to get the prizes in the museum (Refer to Table 1). From the interview of player experience in the gamification website, most players consider that the gamification website attracts players clicking to read; the game levels allows them understanding the content meanings of Juming's sculpture works; and, the rewards and feedback successfully enhance audience's participation in and satisfaction with visiting the museum.

Table 1

The Website of Juming Museum with Gamification

\begin{tabular}{|c|c|}
\hline 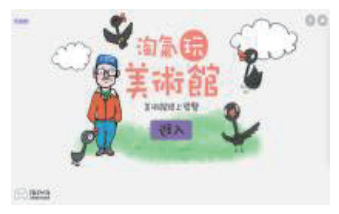 & 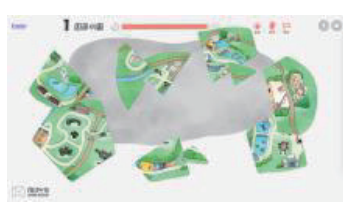 \\
\hline $\begin{array}{l}\text { Website homepage of } \\
\text { Mischievous play museum }\end{array}$ & $\begin{array}{l}\text { The first challenge of } \\
\text { gamification }\end{array}$ \\
\hline 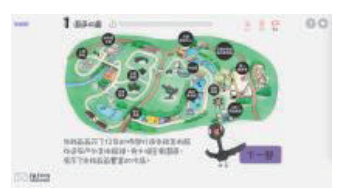 & 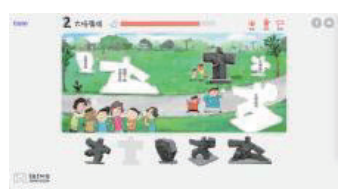 \\
\hline $\begin{array}{l}\text { The first challenge of } \\
\text { gamification }\end{array}$ & $\begin{array}{l}\text { The second challenge of } \\
\text { gamification }\end{array}$ \\
\hline$=\sum_{\text {nx }}^{2}$ & 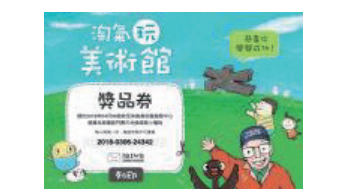 \\
\hline Got success & $\begin{array}{l}\text { The reward mechanics is } \\
\text { applied to encourage } \\
\text { audience to visit the } \\
\text { museum }\end{array}$ \\
\hline
\end{tabular}

"Shihsanhang Museum of Archaeology", a 2-class historical site in Taiwan, promotes the gamification website "Shihsanhang Adventure Archeology Game". The homepage interface presents interesting illustration, and lively roles are designed to attract players' attention. Three games of (1)relics collection, (2)archeological site, and (3)Shihsanhang tribe challenge are designed, and each game contains sub-levels. Each game is presented with the animation of narrative story with linking characters. Before the tasks, the situational animation clearly informs the game rules (Refer to Table 2). Information and knowledge are timely delivered in the game process and the reminder and animation feedback enhance players' comprehension. Accurately practicing commands would increase scores, but it is the opposite for wrong ones, to enhance the excitement. An icon clearly informs the completion of tasks for players understanding the task accomplishment. A ranking system is used for enhancing the competition among players to increase the accomplishment, sociability, and engagement. The game levels are linked by animations of situational stories, and the repetition of same actions is avoided to prevent players from being tired and dull.

Table 2

The The Website of Shihsanhang Museum of Archaeology with Gamification

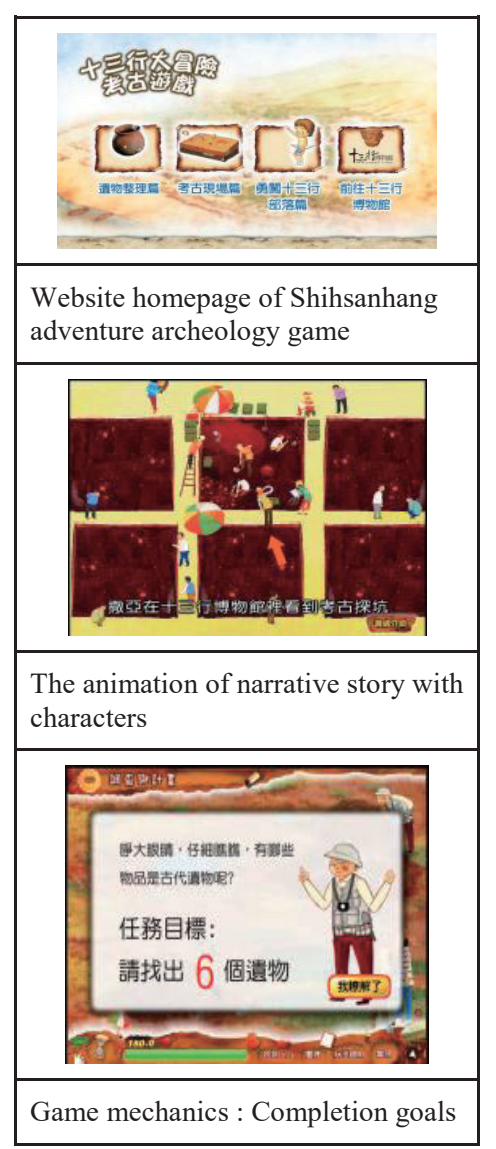

The gamification website "Kids Garden" promoted by National Palace Museum presents the Chinese style illustration as the game interface style. The game mechanism comes from the ancient flowing water, and the body element to drive the game mechanism comes from situational animation (Refer to Table 3). The gamification model turns stiff ancient poems into interesting and attractive games and adds different colors from traditional education to traditional poetry. Players therefore could easily absorb stiff knowledge as well as enhance the entertainment and interests. The game is correlated to the antiques exhibited in National Palace Museum, the situational animation is the major information feedback, and the character animation leads players to the game so that players could better integrate into the situation. Beating a level allows players' engagement and problem solving. The total score after the end of the game would enhance players' accomplishment. 
Table 3

The The Website of National Palace Museum with Gamification

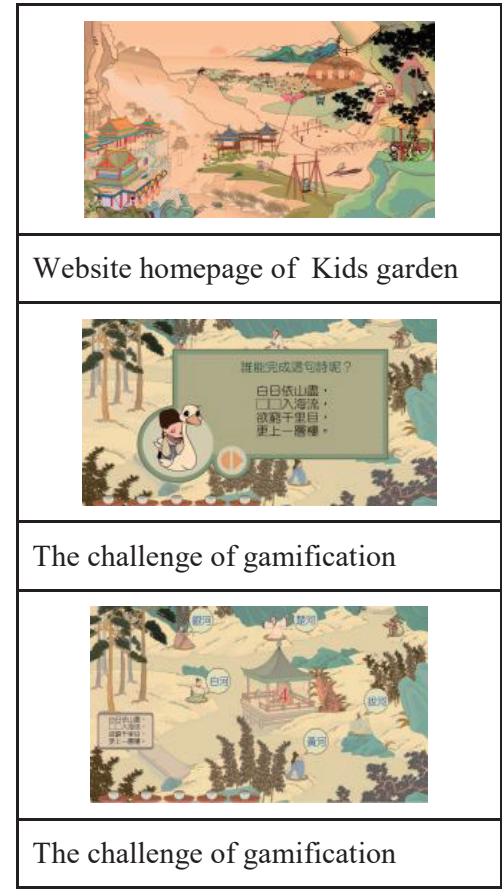

Case analyses are completed at present stage to verify the constructed module in this study, the user test and interview would be further completed to verify the module again.

\section{Conclusion}

The so-called gamification is not a game with high difficulty, but applies game elements to serious tasks or knowledge to successfully attract users. The sampled websites present the common goal to change stiff and dull information into vivid and interesting gamification websites. Meaningful gamification focuses on users to find out user needs. With literature analyses, different theories in the gamification design principles are applied in this study as the reference of future extension of interactive design research. A model applying gamification to website design to enhance effective communication is established for designers exploring and analyzing the needs of users in different cultural contexts and applying to website interface design.

\section{Reference}

[1] Wu, Dai-yun (2015). From game to gamification: preliminary exploration of the marketing and communication of gamification theory. Mass Communication Research, 124, 215-251.

[2] Yeh, Nei-ching (2015). Construction of meaningful gamification library service. Journal of Library and Information Science, 40 (2), 67-76.

[3] Akito Inoue (2013). Play games from thinking, design to marketing: Gamify the gamification era (translated by Lien, Yi-ping). Taipei City: China Times.

[4] Li, Kun-han (2014). Mechanism and design of gamification. The elementary Education Journal, 61 (4), 13-21.

[5] Juming Museum online guidance gamification website, Mischievous Play Museum, http://www.juming.org.tw/opencms/juming/game/

[6] Shihsanhang Advanture Archeology Game, http://www.sshm.ntpc.gov.tw/game/index.html

[7] National Palace Museum kids garden, http:/www.npm.gov.tw/game/home.htm

[8] Barr, P. (2008). Video game values: Play as humancomputer interaction. Doctoral Dissertatio.Victoria University of Wellington.

[9] Deterding, S. (2011). Situated motivational affordances of game elements: A conceptual model. In In CHI 2011 Gamification Workshop Proceedings, Vancouver,BC, Canada.

[10] Deterding, S., Dixon, D., Khaled, R., \& Nacke, L. (2011). Gamification: Toward a definition. CHI 2011, May 7-12, 2011, Vancouver, BC, Canada. http://gamification-research.org/wpcontent/uploads/Deterding-Khaled-NackeDixon.pdfNicholson

[11] Kapp, K. M. (2012). Games, gamification, and the quest for learner engagement. T + D, 66 (6), 64-68.

[12] Nicholson, S. (2012). A user-centered theoretical framework for meaningful gamification. In Games+Learning+Society 8.0, Madison, WI.

[13] Prince, J. D. (2013). Gamification. Journal of Electronic. Resources in Medical Libraries, 10 (3), 162169.

[14] Przybylski, A.K., Rigby, C.S., and Ryan, R.M. (2010) A motivational model of video game engagement. RevGen Psychol 14 (2), 154-166.

[15] Werbach, K., \& Hunter, D. (2012). For the win: How game thinking can revolutionize your business.Philadelphia, PA: Wharton Digital Press.

[16] Werbach, K. (2014). (Re)Defining gamification. The selected works of Kevin Werbach. Retrieved June 12, 2014, from http://works.bepress.com/kevin_werbach /3 (accessed 12 June 2014).

[17] Zichermann, G., \& Cunnigham, C. (2011). Gamification by design: Implementing game mechanics in web and mobile apps. CA: O'Reilly Media. 